\title{
Optimization of foamed plastic technology
}

\author{
Sergey Kozlov ${ }^{1 *}$, Boris Efimov ${ }^{1}$, Ekaterina Bobrova $^{2}$, Ekaterina Zinovieva ${ }^{1}$ and Ekaterina \\ Zhukova $^{1}$
}

${ }^{1}$ Moscow State University of Civil Engineering, Yaroslavskoe shosse, 26, Moscow, 129337, Russia

${ }^{2}$ National research University Higher school of Economics, Moscow, Russia

\begin{abstract}
Annotation. Insulation systems of building structures involve the solution of the following group of tasks: creation of favorable conditions for the work of structural elements and construction as a whole; optimization of heat losses through the insulation shell; creation of comfortable conditions in the room. Such a system would function normally if effective thermal insulation, including polyethylene, were used. The price of polyethylene foam can be reduced without prejudice to the properties in the case of the use of secondary polyethylene foam. The article presents the results of experimental studies, the purpose of which is to optimize the composition of polyethylene foam with the addition of secondary polyethylene, the formation of methods of selection of its composition and the development of systems for the application of products based on polyethylene foam. The article presents the main provisions of the method of analytical optimization, which allows to significantly reducing the material and time costs of processing the results of the experiment. The article deals with aspects of the implementation of construction systems using products based on polyethylene foam in terms of minimizing heat loss through the contact areas. Mandatory criteria for the construction and implementation of insulation systems are safety conditions, including both structural safety (including maintenance-free cycle) and fire safety.
\end{abstract}

\section{Introduction}

Foamed polyethylene is one of the few polymers, which is currently found so widely used in various industries and everyday life. Because of its unique properties in construction it is used: heat, waterproofing of various parts of the building; sheets or flooring between concrete blocks to reduce the load, vibration and prevent cracks, sealing gaskets; heat insulation in storage tanks; noise insulation under carpet and linoleum.

Foam (polyethylene foam) are characterized by a low thermally conductive stew, soundinsulating ability, flexibility and waterproofing your properties [1-7]. In construction, foams with a density ranging from 20 to $80 \mathrm{~kg} / \mathrm{m} 3$ are used. Currently, in our country, according to environmentalists, more than $70 \%$ of all waste is not recycled and sent to landfills.

Of great scientific and practical interest is the creation of filled polymer materials based on recycled polyethylene raw materials. The use of polymer materials from secondary raw materials containing up to $30 \%$ of the filler will allow to release up to $40 \%$ of the primary raw materials and direct it to the production of products that cannot be obtained from the

\footnotetext{
* Corresponding author: ser-31-16@mail.ru
} 
secondary (pressure pipes, packaging films, transport multi-turn containers, etc.). This significantly reduces the deficit of primary polymer raw materials.

\section{Experimental}

Experimental studies are aimed at selecting the optimal content of secondary polyethylene additives and the effect of this additive on the properties of products. The technological aspect of the implementation of this principle is the optimization of the composition based on the methods of mathematical statistics and active experiment [8-10].

As variable factors are adopted: the consumption of recycled polyethylene (X1), the expense poroporo (x2) and pressure in the extruder (X3). As the response functions are taken: the average density of products made of polyethylene foam $(1, \mathrm{~kg} / \mathrm{m} 3)$ and the strength of the plates to compress at $10 \%$ deformation (U2, $\mathrm{kPa}$ ). The strength of plates under compression is accepted as an optimization parameter. The experimental conditions are presented in table. 1.

Table 1. Conditions of the experiment

\begin{tabular}{|c|c|c|c|c|c|}
\hline Factor name Symbol & $\begin{array}{c}\text { Factor } \\
\text { name } \\
\text { Symbol }\end{array}$ & $\begin{array}{c}\text { Factor } \\
\text { name } \\
\text { Symbol }\end{array}$ & $\begin{array}{c}\text { Factor name } \\
\text { Symbol }\end{array}$ & \multicolumn{2}{|c|}{ Factor name Symbol } \\
\hline $\begin{array}{c}\text { Consumption of } \\
\text { secondary } \\
\text { polyethylene, \% }\end{array}$ & $\mathrm{X}_{1}$ & 20 & 10 & 10 & $\mathbf{- 1}$ \\
\hline The flow modifier, \% & $\mathrm{X}_{2}$ & 6 & 1 & 7 & 7 \\
\hline Extruder pressure, $\mathrm{kPa}$ & $\mathrm{X}_{3}$ & 90 & 10 & 80 & 100 \\
\hline
\end{tabular}

Analytical optimization technique is the development of NRU MGSU and tested in the study of technologies of various building materials and the implementation of system solutions based on these materials.

The concept of analytical optimization is based on two statements. First, the resulting mathematical model (in the form of a polynomial) is adequate to the real process, that is, describes it with a certain degree of accuracy. Second, the resulting mathematical model is an algebraic nonlinear function of several variables: all types of actions can be performed with this function using the mathematical analysis tool [11-14].

In fact, analytical optimization consists in determining the extrema of the function of several variables for each of the variables (for which they find partial derivatives for each of the variables and equate them to zero); solving polynomials taking into account the found extreme functions and obtaining regression equations optimized for one or more variables.

\section{Results}

Processing of the experimental results allowed us to obtain regression equations (basic polynomials) that establish a functional relationship between the variable factors and the resulting parameters:

at the confidence interval $\Delta \mathrm{b}=0,8$

$$
\mathrm{U} 1=34+3 \mathrm{X} 1-6 \mathrm{X} 2-3 \mathrm{X} 3+2 \mathrm{X} 1 \mathrm{X} 3
$$

$$
\mathrm{U} 2=160+33 \mathrm{X} 1+25 \mathrm{X} 2+28 \mathrm{X} 3+14 \mathrm{X} 2 \mathrm{X} 3-16 \mathrm{X} 22
$$

at the confidence interval $\Delta \mathrm{b}=14$ 
The analysis of the regression equation coefficients shows that the average density of products made of foam polyethylene $(\mathrm{U} 1, \mathrm{~kg} / \mathrm{m} 3)$ is most influenced by the modifying additive; moreover, with an increase in the consumption of the additive, the density of foam polyethylene decreases (the coefficient at "x2" is equal to "-6"). This is understandable from the point of view of the mechanism of action of maleic anhydride, which under the conditions of polymer melting in the ex-truder has a plasticizing effect on the melt.

An increase in the consumption of secondary polyethylene additives (coefficient at " X1 "equal to" +3") leads to a certain increase in the average density of polyethylene foam, which is due to an increase in the viscosity of the melt in the extruder. The increase in air pressure in the compressor causes a certain decrease in density (the coefficient at "X3" is equal to "-3") due to the better polarization of the polyethylene matrix. The combined effect of the secondary polyethylene flow rate and the pressure in the compressor on the change in the average density affects slightly (the coefficient at "X1X3" is equal to " +2 ", close to the "threshold" confidence interval).

The change in the compressive strength of the plates at $10 \%$ deformation (U2, $\mathrm{kPa}$ ) to the greatest extent is determined by the change in the consumption of secondary polyethylene (the coefficient at "X1" is equal to " $+33 ")$; the consumption of the modifier additive and the change in pressure in the compressor affect the result to a lesser extent. Moreover, the increase in the values of each of the factors causes an increase in strength to some extent (the coefficients at "x2" and "X3" are respectively "25" and "28").

'The combined effect of the secondary polyethylene flow rate and the pressure in the compressor on the strength change is insignificant (the coefficient at "X1X3" is equal to "+14"). The graphical interpretation of the obtained dependences is shown in Fig. 1 and 2.

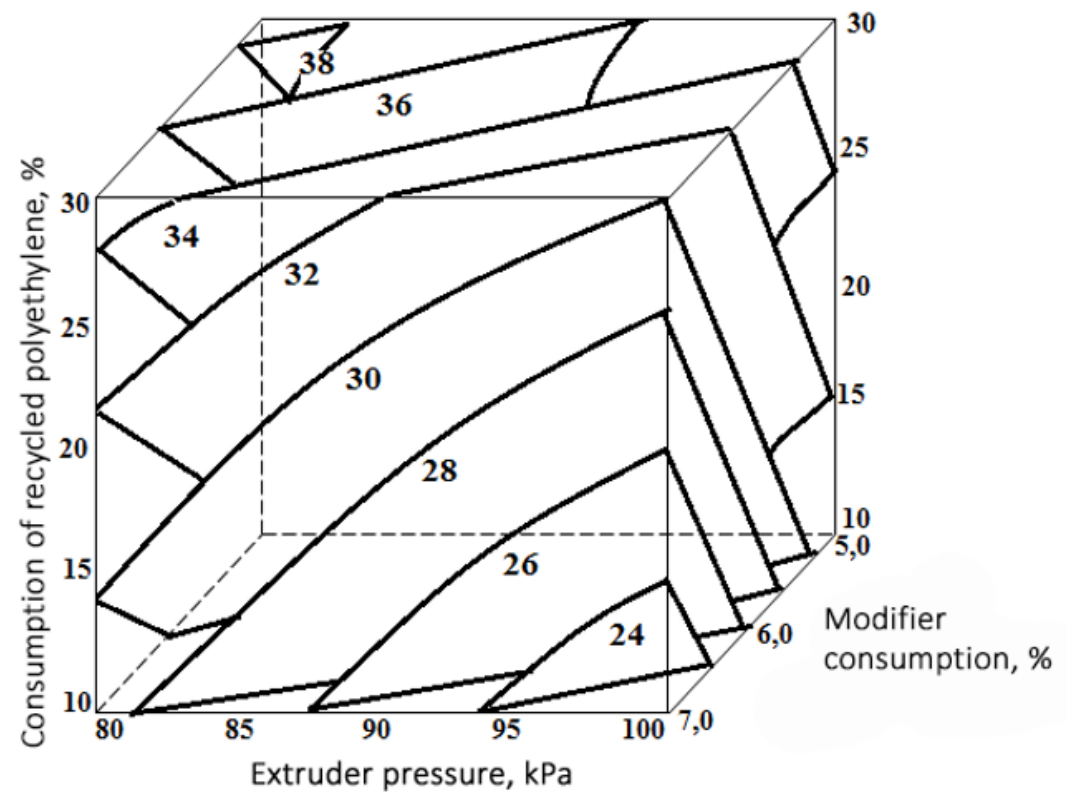

Fig. 1. The dependence of the average density of polyethylene foam $(1, \mathrm{~kg} / \mathrm{m} 3)$ on the consumption of secondary polyethylene and modifier, as well as the air pressure in the extruder 


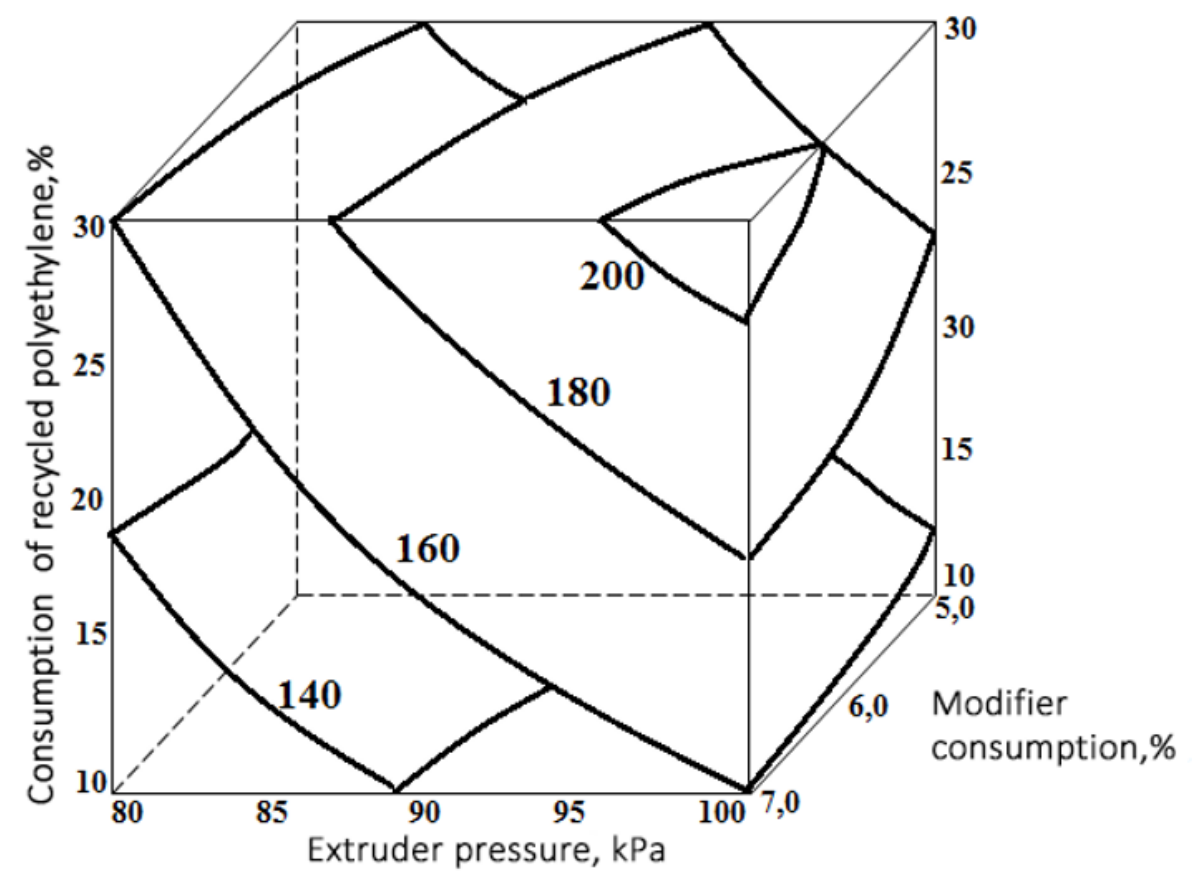

Fig. 2. Dependence of the strength of polyethylene foam plates on compression at $10 \%$ deformation (At $2, \mathrm{kPa}$ ) on the costs of secondary polyethylene and modifier, as well as on the pressure of the air in the extruder

\section{Discussion}

A feature of the polynomial $\mathrm{U} 2(\mathrm{X} 1, \mathrm{x} 2, \mathrm{X} 3)$ is that the dependence of the compressive strength of the plates at $10 \%$ deformation $(\mathrm{U} 2, \mathrm{kPa})$ on the flow rate of the modifier (x2) is non-linear (the coefficient at "X22" equal to "-16"). That is, with an increase in the flow rate of the modifier (ceteris paribus), the strength first increases, and then begins to decrease. To determine the range of values of the flow modifier (x2) at which the strength is maximum, it is possible by analytical optimization.

Thus, the function $\mathrm{U} 2$ (X1, X2, X3) has a local optimum by factor $\mathrm{x} 2$, which is determined by the differential analytical method. Analytical optimization is performed by the function $\mathrm{U} 2(\mathrm{X} 1, \mathrm{x} 2, \mathrm{X} 3)$ :

$$
\partial Y_{2} / \partial X_{2}=25-32 X_{2}=0 \rightarrow X_{2}=25 / 32=0,78
$$

Solving basic polynomials at $\mathrm{x} 2=0.78$ we obtain the following optimization equations:

$$
\begin{gathered}
Y_{1}=29+3 X_{1}-3 X_{3}+2 X_{1} X_{3} \\
Y_{2}=170+33 X_{1}+28 X_{3}+14 X_{1} X_{3}
\end{gathered}
$$

Differentiation of the partial differential equation allowed to establish the optimization function. Next, the calculation of the basic polynomials by the optimization function was carried out, the optimized equations for U1 and U2 were obtained, and a graphical interpretation was carried out, which resulted in the construction of a nomogram for the optimized compositions (Fig. 3).

The actual value of the optimal flow rate of the modifier defined in the coded values $\left(\mathrm{x}_{2}\right)$ is determined on the basis of table data. One: 


$$
X_{2}=\overline{X_{2}}+\Delta X_{2} \times X_{2}=6+1 \times 0,8=6,8 \%
$$

Taking into account the statistical error of the experiment, we obtain the optimal consumption of the modifier: $6.7 \pm 0.2 \%$.

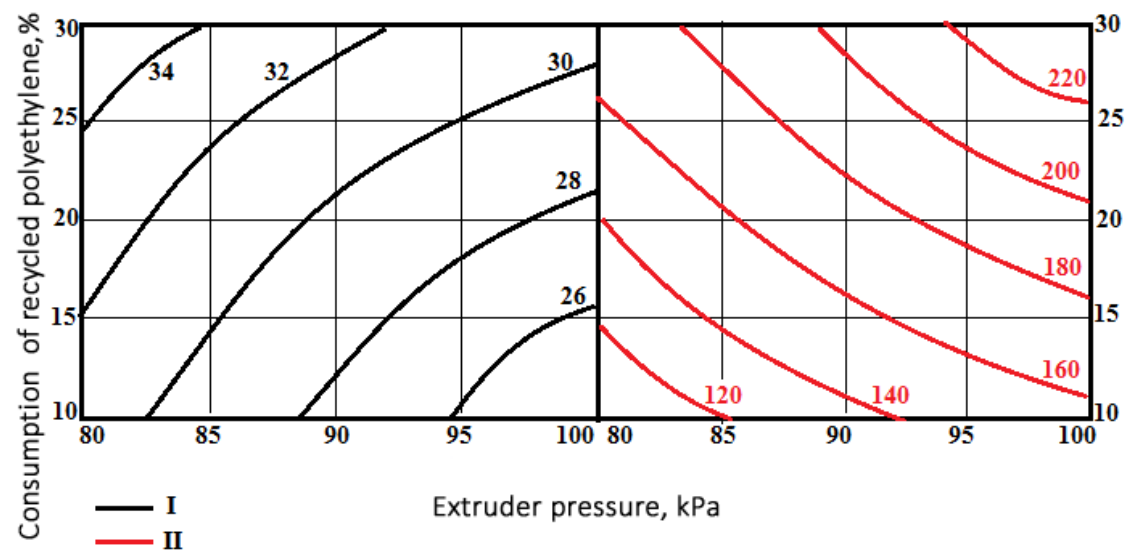

Fig. 3. Nomogram to determine the consumption of secondary polyethylene: I-average density, $\mathrm{kg} / \mathrm{m} 3$; II-compressive strength at $10 \%$ deformation, $\mathrm{kPa}$

Engineering interpretation of the obtained dependences allows us to recommend the following composition for the manufacture of polyethylene foam. Consumption of recycled polyethylene is assumed equal to $25 \%$, flow modifier 7.8 percent. The composition of the foam is associated with the technological parameters and in this case, the pressure in the extruder. The higher the pressure (within the area considered in the experiment), the higher the strength of the resulting foam. At a consumption of secondary polyethylene $25 \%$ and the required strength (compression at $10 \%$ deformation) $200 \mathrm{kPa}$, the pressure created by the co-presser in the extruder should be at the level of 93-94 $\mathrm{kPa}$.

Polyethylene is a high-molecular compound consisting of long chains with branches of different lengths. Depending on the polymerization conditions, i.e. the formation of long molecules, the properties of the resulting polymer depend.

The properties of polyethylene depend on the density, molecular weight of the polymer and molecular weight distribution. With increasing density of polyethylene increases the stiffness of the material, its hardness, tensile strength and resistance to chemicals. Thus, there is a decrease in permeability for water of the PA-RA and gases, toughness, as well as transparency and resistance to cracks under load.

As the molecular weight increases, the impact toughness of the material increases, resistance to tensile and rupture, and resistance to cracking under load. Because the polymer molecules have different lengths, which determines the properties of polymers, the distribution of molecules within the polymer by molecular weight is also important.

Of the study, the results of which are presented in the article show that the properties of polyethylene with the addition of $25 \%$ recycled polyethylene are not fundamentally different from the unsewn properties of polyethylene foam to clean the raw material. Accordingly, all the possibilities of the new material remain [14-16].

The developed material can be used to create a seamless insulation shell with a minimum number of cold bridges and a high degree of uniformity in thermal characteristics. It can be used as a heat - insulating base in floating floors; as insulation of frame buildings and frameless objects (warehouses, hangars and storages) made of profiled metal. 


\section{Conclusions}

Technological features of the creation of a new material are that the introduction of pure polyethylene previously polymerized secondary polyethylene change as the temperature of the melt required for foaming viscosity, and the conditions of its foaming. On the one hand, the melt viscosity increases, which implies an increase in the temperature in the reactor and a change in the pressure in the compressor, since swelling occurs by the kinetic effect of the gas, flow. On the other hand, the polymer molecules (which came into the molten mixture together with the secondary polyethylene) become the centers in the circle of which the matrix of the new material begins to form. Thus, both criteria for the creation of nanostructures are fulfilled: first, the criterion associated with the particle size (molecular level), and second, the criterion due to the self-organization of the structure. In this connection, the developed material and technology may well be classified as nanotechnology, which determines the direction of further research.

\section{References}

1. Insulation systems for buildings and structures based on polyethylene foam. MSBU. IPICSE (2018)

2. Semenov V.S., Rozovskaya T.A., Gubsky A.Yu. Prospects for the use of recycled polyester fibers for the production of heat and sound insulation materials. Stroitel'nye materialy 6 21-24 (2013)

3. Zhukov A.D., Bessonov I.V., Sapelin A.N., Mustafaev R.M. Composite materials with adjustable porosity / Industrial and civil construction 6 58-61 (2014)

4. Zhukov, A.D, Semenov V.S, Gnip, I.J., Vaitkus, S.J. The investigation of expanded polystyrene creep behavior. Proceedings of the XXVI R-S-P Seminar 2017, Theoretical Foundation of Civil Engineering (Warsaw August $19^{\text {th }}-21$ th, 2017), MATEC Web of Conferences $1170018426^{\text {th }}$ R-S-P, (2017)

5. Rumyantsev B.M., Zhukov A.D., Bobrova E.Yu., Smirnova T.V. Technological aspects of the operational durability of mineral fibers Industrial and civil construction 132-36 (2015)

6. Bessonov I.V., Starostin A.V., Oskina V.M. About the form stability of fibrous insulation Vestnik MGSU 3 134-139 (2011)

7. Rumyantsev B.M., Zhukov A.D., Chkunin A.S., Aristov D.I. Optimization of cellular structures Scientific Review 13 128-131 (2017)

8. Zhuk P.M., Zhukov A.D. Normative legal base of environmental assessment of building materials: prospects for improvement, Ecology and industry of Russia 4 52-57 (2018)

9. Gnip I.J., Keršulis V.J., Vaitkus S.J. Analytical description of the creep of expanded polystyrene under compressive loading. Mechanics of Composite materials 41(4) 357364 (2005)

10. Gnip I.Ya., Kerchulis V.I., Vaitkus S.Ya. Confidence intervals predicting the creep deformation of polystyrene foam Construction materials 12 40-44 (2012)

11. Zhukov A.D., Naumova N.V., Mustafayev R.M., Mayorova N.A. Modeling the properties of highly porous materials of combined structure "Industrial and civil construction" 7 48-51 (2014)

12. Umnyakova N.P., Tsygankov V.M., Kuzmin V.A. Experimental Heat Engineering Studies for Rational Design of Wall Structures with Reflecting Heat Insulation. Housing construction 1-2 38-42 (2018)

13. Zhukov A.D., Chugunkov A.V., Khimich A.O. Non-autoclaved low-shrink cellular concrete for monolithic structures Industrial and civil engineering 3 P. 21-22 (2013)

14. Zhukov A.D., Chugunkov A.V., Gudkov P.K. Modeling and optimization of aerated 
concrete technology Vestnik MGSU 4 155-159 (2012)

15. A. D. Zhukov, K. A. Ter-Zakaryan, V. S. Semenov. Insulation systems with the expanded polyethylene application. ScienceDirect IFAC 51 803-807 (2018)

16. Zhukov A.D., Ter-Zakaryan K.A., Zayafarov A.V., Petrovsky Ye.S., Tuchaev D.U. Insulation systems for pitched roofs Roofs and roofs 6 27-29 (2017) 